ductivity of land under cultivation with that of natural communities under the same zonal conditions. Studies of primary production are to be made of tundra, nine types of forest zone, wooded and normal steppe, and in both desert and mountain districts. There is to be a major effort on soil ecology.

The freshwater productivity (PF) programme is also comprehensive. It appears to be organized largely from research already going on. One series of surveys is concerned with representative waters at all trophic levels to build up an integrated picture of typical freshwater communities. Fourteen sites have been chosen; they include Lake Baikal, Lake Sevan (in Armenia), Lake Fahrakush in Azerbaidjan, several lakes in Byelorussia, others in Karelia, tundra lakes, and also reservoirs on the Volga and Dneiper, and the Irkutsk and Bratsk reservoirs on the Angara river, eastern Siberia. A second group of some 20 sites has been chosen to define particular problems relevant to IBP. Two aspects of pollution receive special prominence: the effects of thermal pollution from power station cooling (to be studied in the Ukraine and Moldavia), and the biological factors governing the self-purification of rivers which is being concentrated on the River Daugava in Lithuania. Several exercises in computer modelling are also ir hand.

The marine productivity section (PM) is split up) into work on the Soviet Union's inland seas such as the Black Sea, White Sea and Caspian (5), study of the biological structure and productivity of "the World Ocean" (19), and survey of the biological resources of the World Ocean (7). (The number of topics listed under each of these themes is given in brackets.) Soviet oceanographic ships will clearly be covering great distances during the five years of IBP. The least developed section in the programmeapart from the UM section-is terrestrial conservation. The Soviet Union has a rather active and forwardlooking conservation policy, but the impression is that the conservation authorities are labouring under the massive inventorial work landed on them by the IBP.

\section{Academics on the Air}

IN the spring of 1969 , Professor Walter Perry, now at Edinburgh, will take charge of the Open University, as its first Vice-Chancellor. Professor Perry faces a considerable task, for, in addition to the problems involved in getting an organization for higher education off the ground, he has the added complication of having to put it on the air. The planning committee has produced an outline of the form the university courses should take (see Nature, 21\%, 997; 1968), but the detailed planning will be in Professor Perry's hands. In the meantime, the background work in London is continuing. The pilot study for the survey of potential students has now been made and the complete survey will shortly be made in six different areas, with results coming through in the autumn. This would seem to be a vital task as there is otherwise no definite information on the numbers, age and interests of possible students. A crucial factor in the costs of the university-the fees which will have to be paid to the $\mathrm{BBC}$ for broadcasting courses-has yet to be settled, but costings are expected this week.
Professor Perry, who is 47, is at present professor of pharmacology at Edinburgh. Since 1967 he has been vice-principal of the university with special responsibility for postgraduate education, and with a hand in both financial planning and broad administrative problems. From 1947 to 1952 Professor Perry was on the staff of the Medical Research Council. The following six years were occupied with the Department of

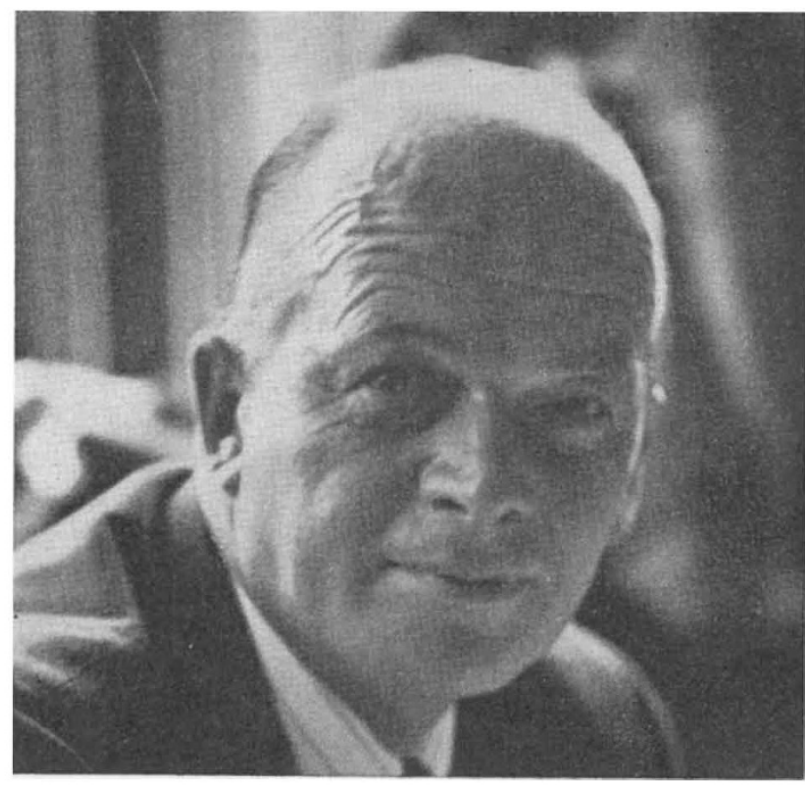

Professor Walter Perry.

Biological Standards at the National Institute for Medical Research, during which time the Salk Institute vaccine for polio was introduced, and as director of the department Professor Perry was responsible for checking the vaccine. In 1965 the MRC set up a unit of brain metabolism research with Professor Perry as its honorary director.

\section{Glasgow Linac}

The University of Glasgow now has the most powerful electron linear accelerator in Britain, a $100 \mathrm{MeV}$ machine at the university's new Kelvin Laboratory, opened on June 10 by Professor P. M. S. Blackett, president of the Royal Society. The linear accelerator is to be used chiefly for research into nuclear structure, where beams of electrons have a number of advantages as probes. Work on the laboratory started in 1963 and was completed in March last year. Since then, the university has developed the instrumentation of the accelerator and carried out a number of experiments with it.

The accelerator itself was built by Vickers Engineering and has three acceleration sections, with provision for a fourth to be added in the future to increase the energy the machine can attain. Radio frequency energy for the accelerator is supplied by three klystrons operating at a peak power of $20 \mathrm{MW}$, and is transferred to the machine by a number of waveguides. Because of heating of the klystrons and waveguides, the accelerator produces pulses of electrons lasting only a few microseconds, with intervals of several milliseconds 